\title{
An Iterative Method with Norm Convergence for a Class of Generalized Equilibrium Problems
}

\author{
Haixia Zhang ${ }^{1}$ and Fenghui Wang ${ }^{2}$ \\ ${ }^{1}$ Department of Mathematics, Henan Normal University, Xinxiang 453007, China \\ ${ }^{2}$ Department of Mathematics, Luoyang Normal University, Luoyang 471022, China \\ Correspondence should be addressed to Fenghui Wang; wfenghui@163.com
}

Received 12 January 2013; Accepted 1 July 2013

Academic Editor: Filomena Cianciaruso

Copyright (c) $2013 \mathrm{H}$. Zhang and F. Wang. This is an open access article distributed under the Creative Commons Attribution License, which permits unrestricted use, distribution, and reproduction in any medium, provided the original work is properly cited.

Recently, Takahashi and Takahashi proposed an iterative algorithm for solving a problem for finding common solutions of generalized equilibrium problems governed by inverse strongly monotone mappings and of fixed point problems for nonexpansive mappings. In this paper, we provide a result that allows for the removal of one condition ensuring the strong convergence of the algorithm.

\section{Introduction}

Let $\mathscr{H}$ be a real Hilbert space and $C$ a nonempty closed convex subset. A generalized equilibrium problem is formulated as a problem of finding a point $x^{*} \in C$ with the property

$$
F\left(x^{*}, y\right)+\left\langle A x^{*}, y-x^{*}\right\rangle \geq 0, \quad \forall y \in C,
$$

where $F: C \times C \rightarrow \mathbb{R}$ is a bifunction and $A: C \rightarrow \mathscr{H}$ is a nonlinear mapping. In particular, if $A$ is the zero mapping, then problem (1) is reduced to an equilibrium problem; find a point $x^{*} \in C$ with the property

$$
F\left(x^{*}, y\right) \geq 0, \quad \forall y \in C .
$$

We will denote by $\operatorname{EP}(F ; A)$ and $\operatorname{EP}(F)$ the solution set of problem (1) and problem (2), respectively. A fixed point problem (FPP) is to find a point $x^{*}$ with the property

$$
x^{*} \in C, \quad S x^{*}=x^{*},
$$

where $S: C \rightarrow C$ is a nonlinear mapping. The set of fixed points of $S$ is denoted as $\operatorname{Fix}(S)$.

The problem under consideration in this paper is to find a common solution of problem (1) and of FPP (3). Namely, we seek a point $x^{*}$ such that

$$
x^{*} \in \operatorname{Fix}(S) \cap \operatorname{EP}(F ; A) .
$$

We consider problem (4) in the case whenever $A$ is a $\nu$ inverse strongly monotone mapping and $S$ is a nonexpansive mapping. To solve problem (4), Takahashi and Takahashi [1] introduced an algorithm which generates a sequence $\left(x_{n}\right)$ by the iterative procedure

$$
\begin{array}{r}
F\left(z_{n}, y\right)+\left\langle A x_{n}, y-z_{n}\right\rangle+\frac{1}{\lambda_{n}}\left\langle y-z_{n}, z_{n}-x_{n}\right\rangle \geq 0, \\
\forall y \in C, \\
x_{n+1}=\beta_{n} x_{n}+\left(1-\beta_{n}\right) S\left[\alpha_{n} u+\left(1-\alpha_{n}\right) z_{n}\right],
\end{array}
$$

where $\left(\alpha_{n}\right) \subseteq[0,1],\left(\beta_{n}\right) \subseteq[0,1]$, and $\left(\lambda_{n}\right) \subseteq[0,2 \nu]$ are chosen so that

$$
\begin{gathered}
0<a \leq \lambda_{n} \leq b<2 \nu, 0<c \leq \beta_{n} \leq d<1, \\
\lim _{n \rightarrow \infty} \alpha_{n}=0, \quad \sum_{n=0}^{\infty} \alpha_{n}=\infty, \\
\left|\lambda_{n}-\lambda_{n+1}\right| \longrightarrow 0 .
\end{gathered}
$$

Under these conditions, they proved that the sequence $\left(x_{n}\right)$ generated by (5) can be strongly convergent to a solution of problem (4).

It is the aim of this paper to continue the study of algorithm (5). We will show that problem (4) is in fact 
a special fixed point problem for a nonexpansive mapping (a composition of a nonexpansive mapping and an averaged mapping). Our approach mainly uses the properties of averaged mappings, which is different from the existing methods invented by Takahashi and Takahashi. Moreover, we shall prove that condition $\left|\lambda_{n}-\lambda_{n+1}\right| \rightarrow 0$ sufficient to guarantee the convergence of algorithm (5) is superfluous.

\section{Preliminaries and Notations}

Notation 1 . $\rightarrow$ strong convergence, $\rightarrow$ weak convergence and $\omega_{w}\left(x_{n}\right)$ the set of the weak cluster points of $\left(x_{n}\right)$.

Denote by $P_{C}$ the projection from $\mathscr{H}$ onto $C$; namely, for $x \in \mathscr{H}, P_{C} x$ is the unique point in $C$ with the property

$$
\left\|x-P_{C} x\right\|=\min _{y \in C}\|x-y\| .
$$

It is well known that $P_{C} x$ is characterized by the inequality

$$
\begin{gathered}
P_{C} x \in C \\
\left\langle x-P_{C} x, z-P_{C} x\right\rangle \leq 0, \quad \forall z \in C .
\end{gathered}
$$

We will use the following notions on nonlinear mappings $T: C \rightarrow \mathscr{H}$.

(i) $T$ is nonexpansive if

$$
\|T x-T y\| \leq\|x-y\|, \quad \forall x, y \in C .
$$

(ii) $T$ is firmly nonexpansive if

$$
\langle T x-T y, x-y\rangle \geq\|T x-T y\|^{2}, \quad \forall x, y \in C .
$$

(iii) $T$ is $\alpha$-averaged if there exist a constant $\alpha \in(0,1)$ and a nonexpansive mapping $S$ such that $T=(1-\alpha) I+\alpha S$, where $I$ is the identity mapping on $\mathscr{H}$.

(iv) $T$ is $\nu$-inverse strongly monotone if there is a constant $\nu>0$ such that

$$
\langle T x-T y, x-y\rangle \geq v\|T x-T y\|^{2}, \quad \forall x, y \in C .
$$

The next lemma is referred to as the demiclosedness principle for nonexpansive mappings (see [2]).

Lemma 1. Let $C$ be a nonempty closed convex subset of $\mathscr{H}$ and $T: C \rightarrow \mathscr{H}$ a nonexpansive mapping with $\operatorname{Fix}(T) \neq \emptyset$. If $\left(x_{n}\right)$ is a sequence in $C$ such that $x_{n} \rightarrow x$ and $(I-T) x_{n} \rightarrow 0$, then $(I-T) x=0$; that is, $x \in \operatorname{Fix}(T)$.

Averaged mappings will play important role in our convergence analysis. We therefore collect some useful properties of averaged mappings (see, e.g., [3-5]).

Lemma 2. The following assertions hold.

(i) $T$ is firmly nonexpansive if and only if $T$ is $1 / 2$ averaged.

(ii) If $T_{i}$ is $v_{i}$-averaged, $i=1,2$, then $T_{1} T_{2}$ is $\left(\nu_{1}+v_{2}-v_{1} v_{2}\right)$ averaged. (iii) If $T: C \rightarrow \mathscr{H}$ is $v$-averaged, then for any $z \in \operatorname{Fix}(T)$ and for all $x \in C$,

$$
\|T x-z\|^{2} \leq\|x-z\|^{2}-\frac{1-v}{v}\|T x-x\|^{2} .
$$

From now on, we assume that $F: C \times C \rightarrow \mathbb{R}$ is a bifunction so that

(A1) $F(x, x)=0$, for all $x \in C$;

(A2) $F$ is monotone; that is, $F(x, y)+F(y, x) \leq$ 0 , for all $x, y \in C$;

(A3) $\lim _{t \downarrow 0} F(t z+(1-t) x, y) \leq F(x, y)$, for all $x, y \in C$;

(A4) for each $x \in C, y \mapsto F(x, y)$ is convex and lower semicontinuous.

Under these assumptions, the following results hold (see [6, 7]).

Lemma 3. Let $F: C \times C \rightarrow \mathbb{R}$ satisfy (A1)-(A4). Then for any $\lambda>0$ and $x \in \mathscr{H}$, there exists $z \in C$ so that

$$
F(z, y)+\frac{1}{\lambda}\langle y-z, z-x\rangle \geq 0, \quad \forall y \in C .
$$

Moreover if $S_{\lambda} x=\{z \in C: F(z, y)+1 / \lambda\langle y-z, z-x\rangle \geq 0$, for all $y \in C\}$, then

(i) $S_{\lambda}$ is single valued and $\operatorname{Fix}\left(S_{\lambda}\right)=\operatorname{EP}(F)$;

(ii) $S_{\lambda}$ is firmly nonexpansive;

(iii) $\mathrm{EP}(F)$ is closed and convex.

We end this section by a useful lemma (see Xu [8]).

Lemma 4. Let $\left(a_{n}\right)$ be a nonnegative real sequence satisfying

$$
a_{n+1} \leq\left(1-\alpha_{n}\right) a_{n}+\alpha_{n} b_{n}
$$

where $\left(\alpha_{n}\right) \subset(0,1)$ and $\left(b_{n}\right)$ are real sequences. Then $a_{n} \rightarrow 0$ provided that

(i) $\sum_{n} \alpha_{n}=\infty, \lim _{n} \alpha_{n}=0$;

(ii) $\lim \sup _{n} b_{n} \leq 0$ or $\sum \alpha_{n}\left|b_{n}\right|<\infty$.

\section{Algorithm and Its Convergence}

We begin with the following lemma.

Lemma 5. Assume that $A: C \rightarrow \mathscr{H}$ is v-inverse strongly monotone mapping for some $\nu>0$. Given a real number $\lambda$ such that $0<\lambda<2 \nu$, set $T_{\lambda}=S_{\lambda}(I-\lambda A)$ with $S_{\lambda}$ defined as in Lemma 3. Then the following assertions hold:

(a) $T_{\lambda}$ is single valued and $\operatorname{Fix}\left(T_{\lambda}\right)=\operatorname{EP}(F ; A)$;

(b) $T_{\lambda}$ is $(2 v+\lambda) / 4 v$-averaged;

(c) given $z \in \mathrm{EP}(F ; A)$, it follows that

$$
\left\|T_{\lambda} x-z\right\|^{2} \leq\|x-z\|^{2}-\frac{2 v-\lambda}{2 \nu+\lambda}\left\|T_{\lambda} x-x\right\|^{2} ;
$$


(d) if $0<\lambda \leq \lambda^{\prime}<2 v$, then for all $x \in C$

$$
\left\|T_{\lambda} x-x\right\| \leq 2\left\|T_{\lambda^{\prime}} x-x\right\| .
$$

Proof. (a) It is readily seen that $T_{\lambda}$ is single valued because $S_{\lambda}$ is single valued. The equality follows from the definition of $S_{\lambda}$

(b) It follows that

$$
\begin{aligned}
&\|(I-2 \nu A) x-(I-2 \nu A) y\|^{2} \\
&=\|(x-y)-2 v(A x-A y)\|^{2} \\
&=\|x-y\|^{2}+4 v^{2}\|A x-A y\|^{2} \\
&-4 v\langle x-y, A x-A y\rangle .
\end{aligned}
$$

Since $A$ is $v$-inverse strongly monotone, $I-2 v A$ is nonexpansive. Observe that

$$
I-\lambda A=\left(1-\frac{\lambda}{2 \nu}\right) I+\frac{\lambda}{2 \nu}(I-2 v A),
$$

which implies that $I-\lambda A$ is $\lambda / 2 \nu$-averaged. Consequently (b) follows from part (ii) of Lemma 2 and (c) follows from part (iii) of Lemma 2.

(d) Let $z_{1}=T_{\lambda} x$ and $z_{2}=T_{\lambda^{\prime}} x$. By definition of $S_{\lambda}$,

$$
F\left(z_{1}, y\right)+\left\langle A x, y-z_{1}\right\rangle+\frac{1}{\lambda}\left\langle y-z_{1}, z_{1}-x\right\rangle \geq 0,
$$

$$
\forall y \in C .
$$

Letting $y=z_{2}$ in (19) yields

$$
F\left(z_{1}, z_{2}\right)+\left\langle A x, z_{2}-z_{1}\right\rangle+\frac{1}{\lambda}\left\langle z_{2}-z_{1}, z_{1}-x\right\rangle \geq 0 .
$$

Similarly,

$$
F\left(z_{2}, z_{1}\right)+\left\langle A x, z_{1}-z_{2}\right\rangle+\frac{1}{\lambda^{\prime}}\left\langle z_{1}-z_{2}, z_{2}-x\right\rangle \geq 0 .
$$

Adding up these inequalities and using the monotonicity of F,

$$
\frac{1}{\lambda}\left\langle z_{2}-z_{1}, z_{1}-x\right\rangle+\frac{1}{\lambda^{\prime}}\left\langle z_{1}-z_{2}, z_{2}-x\right\rangle \geq 0,
$$

or equivalently,

$$
\left\|z_{2}-z_{1}\right\|^{2} \leq\left(1-\frac{\lambda}{\lambda^{\prime}}\right)\left\langle z_{2}-z_{1}, z_{2}-x\right\rangle .
$$

Hence, $\left\|z_{2}-z_{1}\right\| \leq\left\|z_{2}-x\right\|$. By the triangle inequality,

$$
\left\|z_{1}-x\right\| \leq\left\|z_{1}-z_{2}\right\|+\left\|z_{2}-x\right\| \leq 2\left\|z_{2}-x\right\|,
$$

which is the result as desired.

For every $n \geq 0$, if we define $T_{n}=S_{\lambda_{n}}\left(I-\lambda_{n} A\right)$, where $S_{\lambda_{n}}$ is defined as in Lemma 3 , then we can rewrite algorithm (5) as

$$
\begin{gathered}
y_{n}=\alpha_{n} u+\left(1-\alpha_{n}\right) T_{n} x_{n}, \\
x_{n+1}=\beta_{n} x_{n}+\left(1-\beta_{n}\right) S y_{n} .
\end{gathered}
$$

Theorem 6. Let $F: C \times C \rightarrow \mathbb{R}$ be a bifunction satisfying (A1)-(A4), $A: C \rightarrow \mathscr{H}$ a v-inverse strongly monotone mapping for some $v>0$, and $S: C \rightarrow C$ a nonexpansive mapping so that the solution set $\Omega:=\operatorname{Fix}(S) \cap \operatorname{EP}(F ; A)$ is nonempty. If the following conditions hold:

$$
0<a \leq \lambda_{n} \leq b<2 \nu, 0<c \leq \beta_{n} \leq d<1,
$$

$$
\lim _{n \rightarrow \infty} \alpha_{n}=0, \quad \sum_{n=0}^{\infty} \alpha_{n}=\infty,
$$

then the sequence $\left(x_{n}\right)$ generated by (25) converges strongly to $x^{*}=P_{\Omega} u$.

Before proving the theorem, we need some lemmas.

Lemma 7. Let the conditions in Theorem 6 be satisfied. If $\left(x_{n}\right)$ and $\left(y_{n}\right)$ are the sequences generated by (25), then both $\left(x_{n}\right)$ and $\left(y_{n}\right)$ are bounded.

Proof. Let $z \in \Omega$ be fixed. We have

$$
\begin{aligned}
\left\|x_{n+1}-z\right\| & \leq\left\|\left(1-\beta_{n}\right)\left(y_{n}-z\right)+\beta_{n}\left(x_{n}-z\right)\right\| \\
& \leq\left(1-\beta_{n}\right)\left\|y_{n}-z\right\|+\beta_{n}\left\|x_{n}-z\right\| ;
\end{aligned}
$$

on the other hand,

$$
\begin{aligned}
\left\|y_{n}-z\right\| & =\left\|\alpha_{n}(u-z)+\left(1-\alpha_{n}\right)\left(T_{n} x_{n}-z\right)\right\| \\
& \leq\left(1-\alpha_{n}\right)\left\|x_{n}-z\right\|+\alpha_{n}\|u-z\| .
\end{aligned}
$$

Altogether

$$
\begin{aligned}
\left\|x_{n+1}-z\right\| \leq & {\left[1-\alpha_{n}\left(1-\beta_{n}\right)\right]\left\|x_{n}-z\right\| } \\
& +\alpha_{n}\left(1-\beta_{n}\right)\|u-z\| .
\end{aligned}
$$

By induction, $\left(x_{n}\right)$ is bounded and so is $\left(y_{n}\right)$.

Lemma 8. Let the conditions in Theorem 6 be satisfied. If $\| x_{n}-$ $T_{n} x_{n} \| \rightarrow 0$ and $\left\|x_{n}-S y_{n}\right\| \rightarrow 0$, then $\left\|x_{n}-y_{n}\right\| \rightarrow 0$ and $\omega_{w}\left(x_{n}\right) \subseteq \Omega$.

Proof. Let $T_{a}=S_{a}(I-a A)$. By part (d) of Lemma 5,

$$
\left\|x_{n}-T_{a} x_{n}\right\| \leq 2\left\|x_{n}-T_{n} x_{n}\right\| \longrightarrow 0 .
$$

Since $T_{a}$ is nonexpansive, applying the demiclosedness principle yields

$$
\omega_{w}\left(x_{n}\right) \subseteq \operatorname{Fix}\left(T_{a}\right)=\operatorname{EP}(F ; A) .
$$

On the other hand, we see that

$$
\begin{aligned}
\left\|x_{n}-y_{n}\right\| & =\left\|\alpha_{n}\left(u-x_{n}\right)+\left(1-\alpha_{n}\right)\left(T_{n} x_{n}-x_{n}\right)\right\| \\
& \leq \alpha_{n}\left\|u-x_{n}\right\|+\left\|T_{n} x_{n}-x_{n}\right\| \longrightarrow 0,
\end{aligned}
$$

which implies that

$$
\begin{aligned}
\left\|x_{n}-S x_{n}\right\| & \leq\left\|x_{n}-S y_{n}\right\|+\left\|S y_{n}-S x_{n}\right\| \\
& \leq\left\|x_{n}-S y_{n}\right\|+\left\|y_{n}-x_{n}\right\| \longrightarrow 0 .
\end{aligned}
$$

Using again the demiclosedness principle gets the desired result. 
Proof of Theorem 6. Let $x^{*}=P_{\Omega} u$. Using Lemma 5(c), we have

$$
\left\|T_{n} x_{n}-x^{*}\right\|^{2} \leq\left\|x_{n}-x^{*}\right\|^{2}-\frac{2 v-\lambda_{n}}{2 v+\lambda_{n}}\left\|T_{n} x_{n}-x_{n}\right\|^{2} .
$$

By the subdifferential inequality,

$$
\begin{aligned}
\left\|y_{n}-x^{*}\right\|^{2}= & \left\|\alpha_{n}\left(u-x^{*}\right)+\left(1-\alpha_{n}\right)\left(T_{n} x_{n}-x^{*}\right)\right\|^{2} \\
\leq & \left(1-\alpha_{n}\right)\left\|T_{n} x_{n}-x^{*}\right\|^{2} \\
& +2 \alpha_{n}\left\langle u-x^{*}, y_{n}-x^{*}\right\rangle \\
\leq & \left(1-\alpha_{n}\right)\left\|x_{n}-x^{*}\right\|^{2} \\
& +2 \alpha_{n}\left\langle u-x^{*}, y_{n}-x^{*}\right\rangle \\
& -\frac{\left(1-\alpha_{n}\right)\left(2 v-\lambda_{n}\right)}{2 \nu+\lambda_{n}}\left\|T_{n} x_{n}-x_{n}\right\|^{2},
\end{aligned}
$$

which implies that

$$
\begin{aligned}
\left\|x_{n+1}-x^{*}\right\|^{2}= & \beta_{n}\left\|x_{n}-x^{*}\right\|^{2}+\left(1-\beta_{n}\right)\left\|S y_{n}-x^{*}\right\|^{2} \\
& -\beta_{n}\left(1-\beta_{n}\right)\left\|S y_{n}-x_{n}\right\|^{2} \\
\leq & \beta_{n}\left\|x_{n}-x^{*}\right\|^{2}+\left(1-\beta_{n}\right)\left\|y_{n}-x^{*}\right\|^{2} \\
& -\beta_{n}\left(1-\beta_{n}\right)\left\|S y_{n}-x_{n}\right\|^{2} \\
\leq & \beta_{n}\left\|x_{n}-x^{*}\right\|^{2}+\left(1-\beta_{n}\right) \\
& \times\left(1-\alpha_{n}\right)\left\|x_{n}-x^{*}\right\|^{2} \\
& -\frac{\left(1-\alpha_{n}\right)\left(1-\beta_{n}\right)\left(2 v-\lambda_{n}\right)}{2 \nu+\lambda_{n}} \\
& \times\left\|T_{n} x_{n}-x_{n}\right\|^{2}+2 \alpha_{n}\left(1-\beta_{n}\right) \\
& \times\left\langle u-x^{*}, y_{n}-x^{*}\right\rangle-\beta_{n}\left(1-\beta_{n}\right) \\
& \times\left\|S y_{n}-x_{n}\right\|^{2} .
\end{aligned}
$$

By our assumption, there exists $\varepsilon>0$ so that for all $n \geq 0$,

$$
\frac{\left(1-\alpha_{n}\right)\left(1-\beta_{n}\right)\left(2 \nu-\lambda_{n}\right)}{2 \nu+\lambda_{n}} \geq \varepsilon,
$$

and $1-\beta_{n} \geq \beta_{n}\left(1-\beta_{n}\right) \geq \varepsilon$. Consequently,

$$
\begin{aligned}
\left\|x_{n+1}-x^{*}\right\|^{2} \leq & \left(1-\varepsilon \alpha_{n}\right)\left\|x_{n}-x^{*}\right\|^{2} \\
& -\varepsilon\left(\left\|T_{n} x_{n}-x_{n}\right\|^{2}+\left\|S y_{n}-x_{n}\right\|^{2}\right) \\
& +2 \alpha_{n}\left(1-\beta_{n}\right)\left\langle u-x^{*}, y_{n}-x^{*}\right\rangle .
\end{aligned}
$$

Set $s_{n}=\left\|x_{n+1}-x^{*}\right\|^{2}$, and let $\left(s_{n_{k}}\right)$ be a subsequence so that it includes all elements in $\left\{s_{n}\right\}$ with the property; each of them is less than or equal to the term after it. Following an idea developed by Maingé [9], we next consider two possible cases on $\left(s_{n_{k}}\right)$.

Case 1. Assume that $\left\{s_{n_{k}}\right\}$ is finite. Then there exists $N \in \mathbb{N}$ so that $s_{n}>s_{n+1}$ for all $n \geq N$, and therefore $\left\{s_{n}\right\}$ must be convergent. It follows from (38) that

$$
\varepsilon\left(\left\|T_{n} x_{n}-x_{n}\right\|^{2}+\left\|S y_{n}-x_{n}\right\|^{2}\right) \leq M \alpha_{n}+\left(s_{n}-s_{n+1}\right),
$$

where $M>0$ is a sufficiently large real number. Consequently, both $\left\|T_{n} x_{n}-x_{n}\right\|$ and $\left\|S y_{n}-x_{n}\right\|$ converge to zero, and by Lemma 8 we conclude that $\left\|y_{n}-x_{n}\right\| \rightarrow 0$ and $\omega_{w}\left(x_{n}\right) \subseteq \Omega$. Hence,

$$
\begin{aligned}
\limsup _{n \rightarrow \infty}\left\langle u-x^{*}, y_{n}-x^{*}\right\rangle & =\limsup _{n \rightarrow \infty}\left\langle u-x^{*}, x_{n}-x^{*}\right\rangle \\
& =\max _{w \in \omega_{w}\left(x_{n}\right)}\left\langle u-x^{*}, w-x^{*}\right\rangle \leq 0,
\end{aligned}
$$

where the inequality uses (8). It then follows from (38) that

$$
s_{n+1} \leq\left(1-\varepsilon \alpha_{n}\right) s_{n}+2 \alpha_{n}\left(1-\beta_{n}\right)\left\langle u-x^{*}, y_{n}-x^{*}\right\rangle \text {. }
$$

We therefore apply Lemma 4 to conclude that $s_{n} \rightarrow 0$.

Case 2. Assume now that $\left\{s_{n_{k}}\right\}$ is infinite. Let $n \in \mathbb{N}$ be fixed. Then there exists $k \in \mathbb{N}$ so that $n_{k} \leq n \leq n_{k+1}$. By the choice of $\left\{s_{n_{k}}\right\}$, we see that $s_{n_{k}+1}$ is the largest one among $\left\{s_{n_{k}}, s_{n_{k}+1}, \ldots, s_{n_{k+1}}\right\}$; in particular

$$
s_{n_{k}} \leq s_{n_{k}+1}, \quad s_{n} \leq s_{n_{k}+1} .
$$

Then we deduce from (38) that

$$
\varepsilon\left(\left\|T_{n_{k}} x_{n_{k}}-x_{n_{k}}\right\|^{2}+\left\|S y_{n_{k}}-x_{n_{k}}\right\|^{2}\right) \leq M \alpha_{n_{k}} \longrightarrow 0 .
$$

Applying Lemma 8 yields $\left\|y_{n_{k}}-x_{n_{k}}\right\| \rightarrow 0$ and $\omega_{w}\left(x_{n_{k}}\right) \subseteq \Omega$. Similarly

$$
\limsup _{n \rightarrow \infty}\left\langle u-x^{*}, y_{n_{k}}-x^{*}\right\rangle \leq 0 \text {. }
$$

It follows again from (38) and inequality (42) that

$$
s_{n_{k}} \leq 2\left(1-\beta_{n_{k}}\right)\left\langle u-x^{*}, y_{n_{k}}-x^{*}\right\rangle \text {. }
$$

Taking lim sup in (44) yields

$$
\limsup _{k \rightarrow \infty} s_{n_{k}} \leq 0 \Longrightarrow s_{n_{k}} \longrightarrow 0 \text {. }
$$

Moreover, we deduce from algorithm (25) that

$$
\begin{aligned}
\sqrt{s_{n_{k}+1}} & =\left\|\left(x_{n_{k}}-x^{*}\right)-\left(x_{n_{k}}-x_{n_{k}+1}\right)\right\| \\
& \leq \sqrt{s_{n_{k}}}+\left\|x_{n_{k}}-x_{n_{k}+1}\right\| \leq \sqrt{s_{n_{k}}}+\left\|x_{n_{k}}-S y_{n_{k}}\right\|,
\end{aligned}
$$

which together with (43) implies that $s_{n_{k}+1} \rightarrow 0$. Consequently $s_{n} \rightarrow 0$ immediately follows from (42). 


\section{Applications}

In this section we present several applications. First we consider a problem for finding a common solution of equilibrium problem (2) and fixed point problem (3); namely, find $x^{*} \in C$ so that

$$
x^{*} \in \operatorname{EP}(F) \cap \operatorname{Fix}(S) .
$$

Taking $A=0$ in Theorem 6 and noting that zero mapping is $\nu$-inverse strongly monotone for any positive number $\nu$, one can easily get the following.

Corollary 9. Let $F: C \times C \rightarrow \mathbb{R}$ be a bifunction satisfying (A1)-(A4) and $S: C \rightarrow C$ a nonexpansive mapping so that the solution set of problem (48) is nonempty. Given $u \in C$, let $\left(x_{n}\right)$ generated by the iterative algorithm:

$$
\begin{gathered}
F\left(z_{n}, y\right)+\frac{1}{\lambda_{n}}\left\langle y-z_{n}, z_{n}-x_{n}\right\rangle \geq 0, \quad \forall y \in C, \\
x_{n+1}=\beta_{n} x_{n}+\left(1-\beta_{n}\right) S\left[\left(1-\alpha_{n}\right) u+\alpha_{n} z_{n}\right] .
\end{gathered}
$$

If the following conditions hold:

$$
\begin{gathered}
0<a \leq \lambda_{n} \leq b<\infty, 0<c \leq \beta_{n} \leq d<1, \\
\lim _{n \rightarrow \infty} \alpha_{n}=0, \quad \sum_{n=0}^{\infty} \alpha_{n}=\infty,
\end{gathered}
$$

then the sequence $\left(x_{n}\right)$ converges strongly to a solution of problem (48).

A variational inequality problem (VIP) is formulated as a problem of finding a point $x^{*}$ with the property

$$
x^{*} \in C, \quad\left\langle A x^{*}, z-x^{*}\right\rangle \geq 0, \quad \forall z \in C .
$$

We will denote the solution set of VIP $(51)$ by VI $(A ; C)$. Next we consider a problem for finding a common solution of variational inequality problem (51) and of fixed point problem (3), namely; find $x^{*} \in C$ so that

$$
x^{*} \in \operatorname{VI}(A ; C) \cap \operatorname{Fix}(S) .
$$

Taking $F=0$ in (1), we note that the generalized equilibrium problem is reduced to the variational problem (51). Thus applying Theorem 6 gets the following.

Corollary 10. Let $A: C \rightarrow \mathscr{H}$ be $v$-inverse strongly monotone mapping and $S: C \rightarrow C$ a nonexpansive mapping so that the solution set of problem (52) is nonempty. Given $u \in C$, let $\left(x_{n}\right)$ generated by the iterative algorithm:

$$
\begin{gathered}
z_{n}=P_{C}\left(x_{n}-\lambda_{n} A x_{n}\right), \\
x_{n+1}=\beta_{n} x_{n}+\left(1-\beta_{n}\right) S\left[\left(1-\alpha_{n}\right) u+\alpha_{n} z_{n}\right] .
\end{gathered}
$$

If the following conditions hold:

$$
\begin{gathered}
0<a \leq \lambda_{n} \leq b<2 \nu, \quad 0<c \leq \beta_{n} \leq d<1, \\
\lim _{n \rightarrow \infty} \alpha_{n}=0, \quad \sum_{n=0}^{\infty} \alpha_{n}=\infty,
\end{gathered}
$$

then the sequence $\left(x_{n}\right)$ converges strongly to a solution of problem (52).

Consider the optimization problem of finding a point $x^{*} \in C$ with the property

$$
f\left(x^{*}\right)=\min _{x \in C} f(x),
$$

where $f: \mathscr{H} \rightarrow \mathbb{R}$ is a convex and differentiable function. We say that the differential $\nabla f$ is $1 / \nu$-Lipschitz continuous, if

$$
\|\nabla f(x)-\nabla f(y)\| \leq \frac{1}{v}\|x-y\|, \quad \forall x, y \in \mathscr{H} .
$$

Denote by $\operatorname{Argmin}(C ; f)$ the solution set of problem (55). Finally we consider a problem for finding a common solution of optimization problem (55) and of fixed point problem (3), namely; find $x^{*} \in C$ so that

$$
x^{*} \in \operatorname{Argmin}(C ; f) \cap \operatorname{Fix}(S) \text {. }
$$

By [10, Lemma 5.13], problem (55) is equivalent to the variational inequality problem

$$
\left\langle\nabla f\left(x^{*}\right), x^{*}-z\right\rangle \geq 0, \quad \forall z \in C .
$$

Taking $A=\nabla f$ in Corollary 10, we have the following result.

Corollary 11. Let $f: \mathscr{H} \rightarrow \mathbb{R}$ be a convex and differentiable function so that $\nabla f$ is $1 / \nu$-Lipschitz continuous. Let $S: C \rightarrow C$ be a nonexpansive mapping so that the solution set of problem (57) is nonempty. Given $u \in C$, let $\left(x_{n}\right)$ generated by

$$
\begin{gathered}
z_{n}=P_{C}\left(x_{n}-\lambda_{n} \nabla f\left(x_{n}\right)\right), \\
x_{n+1}=\beta_{n} x_{n}+\left(1-\beta_{n}\right) S\left[\left(1-\alpha_{n}\right) u+\alpha_{n} z_{n}\right] .
\end{gathered}
$$

If the following conditions hold:

$$
\begin{gathered}
0<a \leq \lambda_{n} \leq b<2 \nu, 0<c \leq \beta_{n} \leq d<1, \\
\lim _{n \rightarrow \infty} \alpha_{n}=0, \quad \sum_{n=0}^{\infty} \alpha_{n}=\infty,
\end{gathered}
$$

then the sequence $\left(x_{n}\right)$ converges strongly to a solution of problem (57).

Proof. It suffices to note that if $\nabla f$ is $1 / \nu$-Lipschitz continuous, then it is $\nu$-inverse strongly monotone mapping (see [11, Corollary 10]). Consequently Corollary 10 applies and the result immediately follows.

Remark 12. We can further apply the previous method to find a common solution for fixed point and split feasibility problems, as well as for fixed point and convex constrained linear inverse problems (see [12]).

\section{Acknowledgment}

This work is supported by the National Natural Science Foundation of China, Tianyuan Foundation (11226227). 


\section{References}

[1] S. Takahashi and W. Takahashi, "Strong convergence theorem for a generalized equilibrium problem and a nonexpansive mapping in a Hilbert space," Nonlinear Analysis. Theory, Methods \& Applications, vol. 69, no. 3, pp. 1025-1033, 2008.

[2] K. Goebel and W. A. Kirk, Topics in Metric Fixed Point Theory, vol. 28, Cambridge University Press, Cambridge, UK, 1990.

[3] C. Byrne, "A unified treatment of some iterative algorithms in signal processing and image reconstruction," Inverse Problems, vol. 20, no. 1, pp. 103-120, 2004.

[4] P. L. Combettes, "Solving monotone inclusions via compositions of nonexpansive averaged operators," Optimization, vol. 53, no. 5-6, pp. 475-504, 2004.

[5] H.-K. Xu, "Averaged mappings and the gradient-projection algorithm," Journal of Optimization Theory and Applications, vol. 150, no. 2, pp. 360-378, 2011.

[6] E. Blum and W. Oettli, "From optimization and variational inequalities to equilibrium problems," The Mathematics Student, vol. 63, no. 1-4, pp. 123-145, 1994.

[7] S. D. Flåm and A. S. Antipin, "Equilibrium programming using proximal-like algorithms," Mathematical Programming, vol. 78, no. 1, pp. 29-41, 1997.

[8] H.-K. Xu, "Iterative algorithms for nonlinear operators," Journal of the London Mathematical Society, vol. 66, no. 1, pp. 240-256, 2002.

[9] P.-E. Maingé, "Strong convergence of projected subgradient methods for nonsmooth and nonstrictly convex minimization," Set-Valued Analysis, vol. 16, no. 7-8, pp. 899-912, 2008.

[10] H. W. Engl, M. Hanke, and A. Neubauer, Regularization of Inverse Problems, Springer, Dordrecht, The Netherlands, 1996.

[11] J.-B. Baillon and G. Haddad, "Quelques propriétés des opérateurs angle-bornés et $n$-cycliquement monotones," Israel Journal of Mathematics, vol. 26, no. 2, pp. 137-150, 1977.

[12] F. Wang and H.-K. Xu, "Strongly convergent iterative algorithms for solving a class of variational inequalities," Journal of Nonlinear and Convex Analysis, vol. 11, no. 3, pp. 407-421, 2010. 


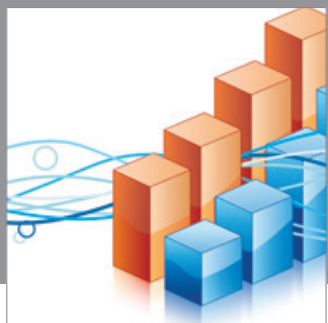

Advances in

Operations Research

mansans

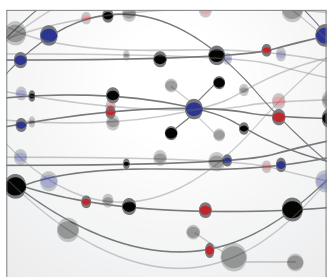

The Scientific World Journal
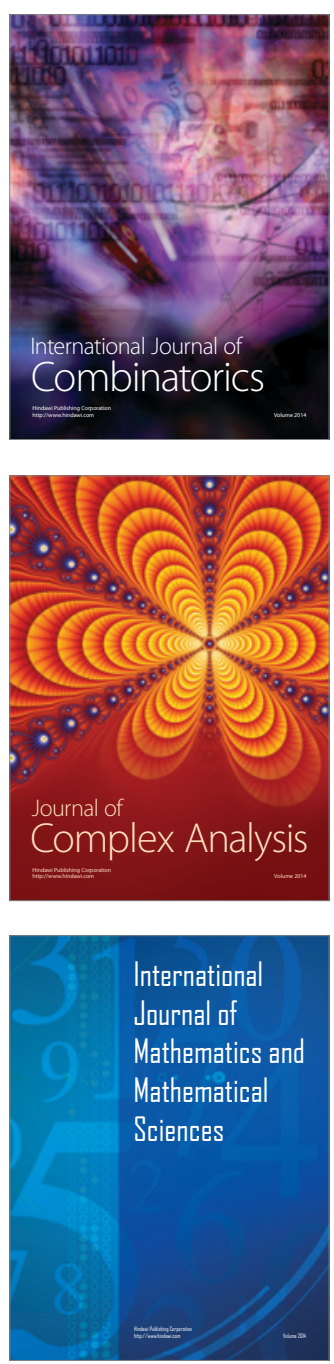
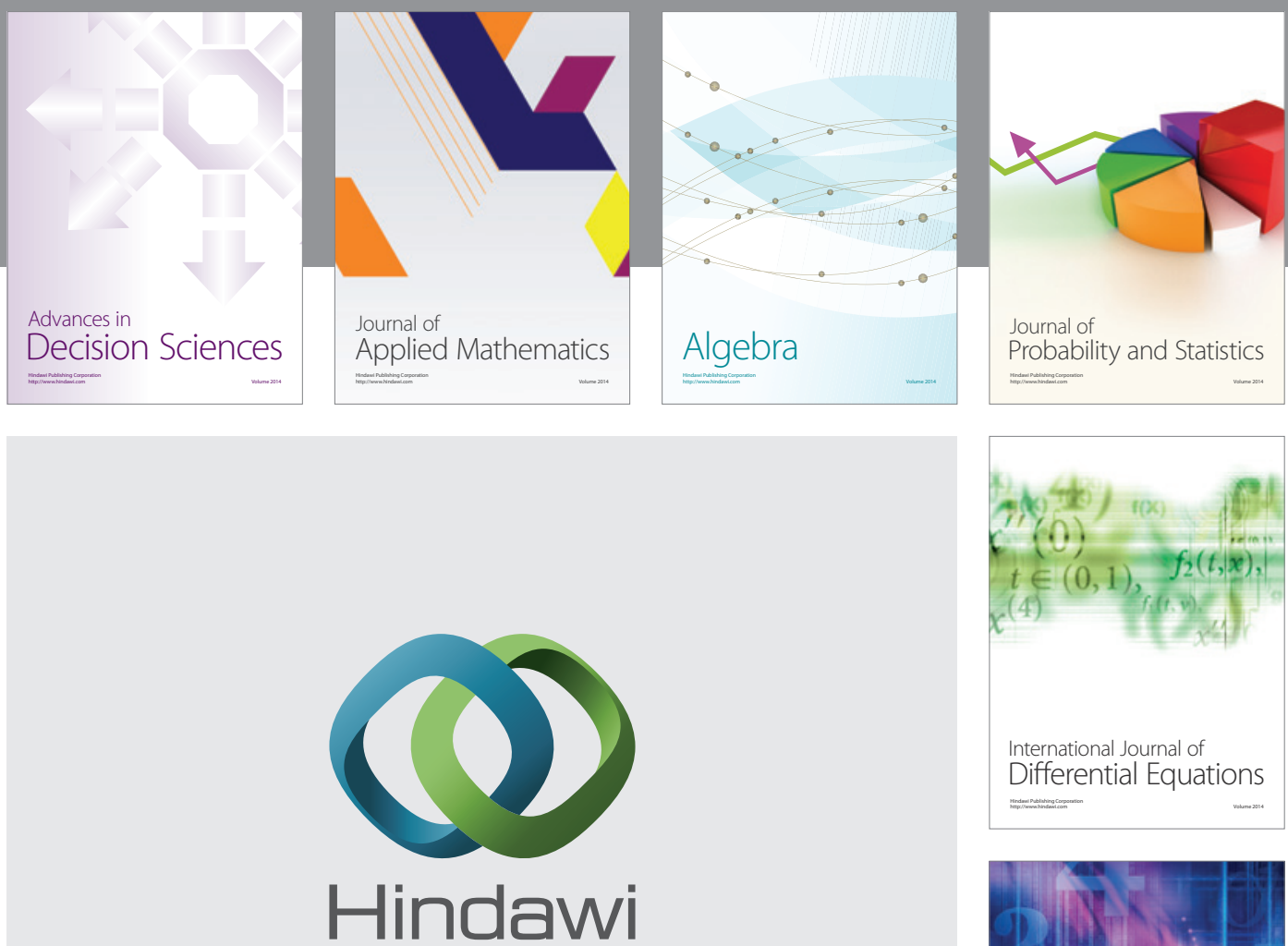

Submit your manuscripts at http://www.hindawi.com
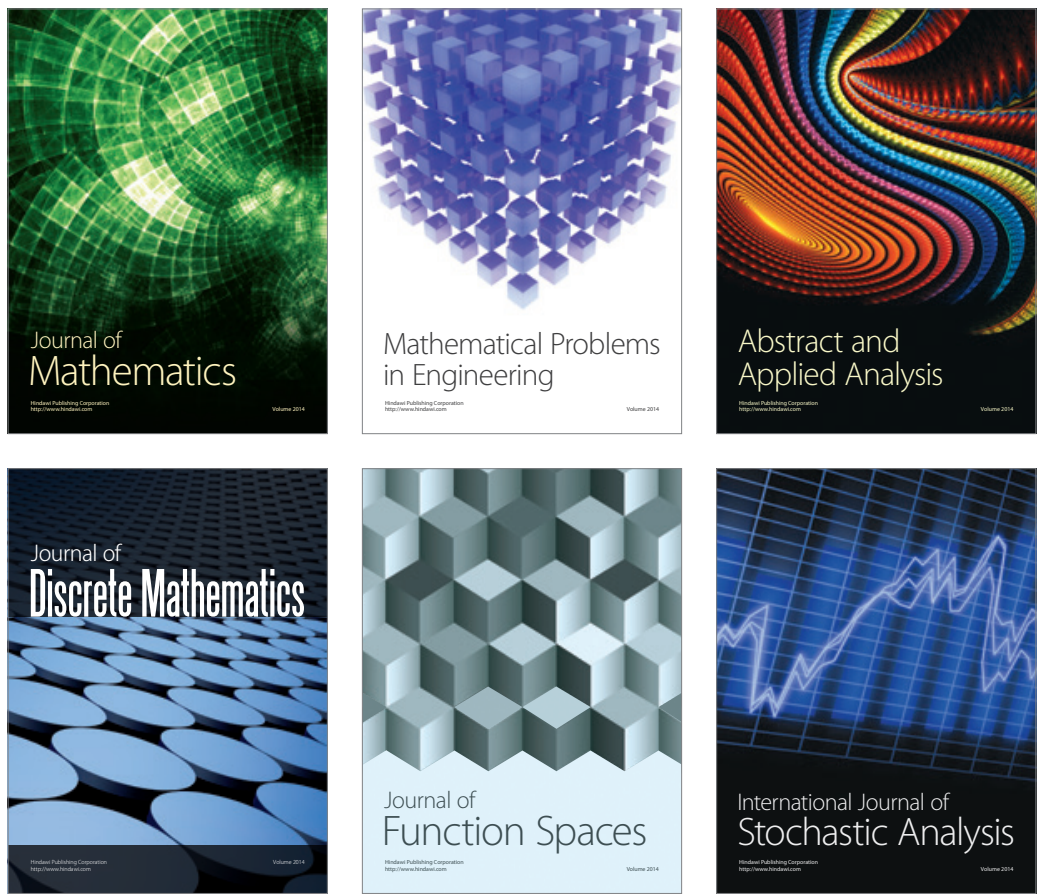

Journal of

Function Spaces

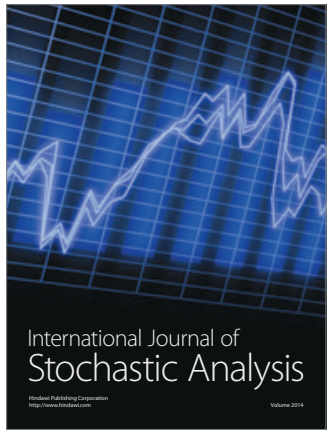

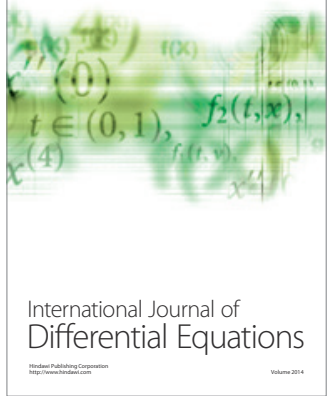
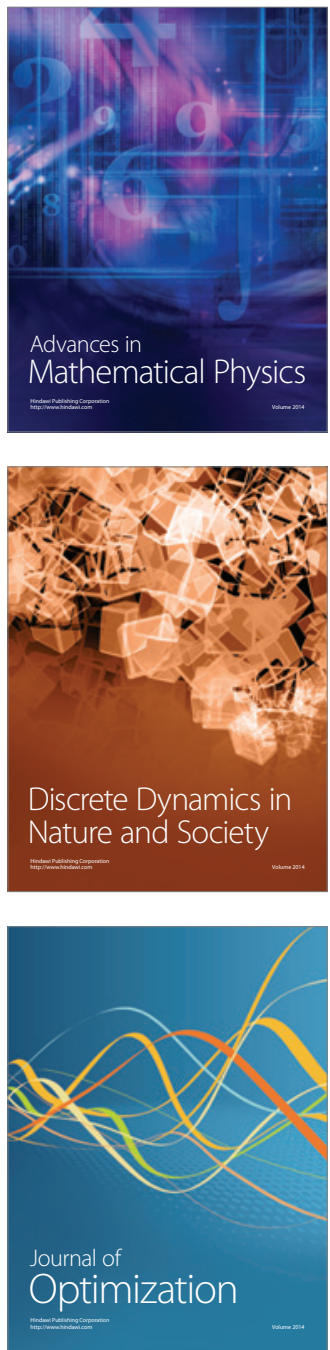